\title{
Creation of an end-to-end customs control system as an economic security tool
}

\author{
Aleksander Aleksandrovich Berzan ${ }^{*}$ and Svetlana Anatolievna Miklava \\ RUDN University, Customs Department, Moscow, Russia
}

\begin{abstract}
The purpose of the study is to identify ways to create a system of end-to-end customs control which would improve the efficiency of the activities of customs authorities and increase the level of economic security of the state. The research used methods of analysis and synthesis, formal logical, and comparative-legal method. The analysis of the customs control system resulted in the identified problems that do not allow increasing the efficiency of customs control and the level of economic security of the state. To solve them, the authors propose to organise the collection of primary information at checkpoints across the state border based on the use of objective control means, and to ensure its availability during subsequent customs operations including when declaring goods and in the process of customs control after the release of goods. In addition, it is proposed to ensure the interaction of customs authorities with other state bodies, the introduction of the institution of customs audit and the implementation of a mechanism to stimulate companies to exit the shadow sector of the economy. The novelty of the research is the proposed model of the end-to end control system, which ensures an increase in the efficiency of customs authorities and the level of economic security of the state.

Keywords: customs control, customs audit, economic security, regulation of foreign economic activity
\end{abstract}

\section{Introduction}

For a long time, our country has been trying to build an economy that would ensure the economic security of the state. However, due to a significant number of threats, it has not yet been possible to solve the problem of ensuring economic security. One of the key elements of the shadow economy is 'grey schemes' for the movement of goods across the customs border of the Eurasian Economic Union (EAEU). One of the reasons for the existence of these schemes is the lack of synchronization of functioning in the customs control system. The solution to the problem can be the formation of a system of end-to-end customs control of goods. The customs authorities of the Russian Federation have already created certain elements of such a system, but the problem of creating a system as a whole has not yet been resolved.

The purpose of this article is finding the ways to solve it. To achieve the goal, it is necessary to solve the following tasks: analyse the current state of customs control, identify

\footnotetext{
* Corresponding author: berzan-aa@rudn.ru

the main problems in its organisation, propose ways to solve them taking into

account the functioning of the control system at various stages of customs
} 
operations.

\section{Results and discussion}

The Customs Service of the Russian Federation is a part of the state administration system. The quality of performance of control functions by customs authorities directly affects many elements of the state's economic system for which it is very important to create a control system that maximizes the solution of strategic goals. In the field of economic security, they consist in increasing resilience to the impact of external and internal challenges and threats, and in ensuring economic growth. The achievement of these goals is significantly influenced by the high level of criminalization and corruption in the economic sphere and the preservation of a significant share of the shadow economy [1].

This threat has to be resisted by the customs authorities. The achievement of these goals can be facilitated by the construction of a control system aimed at ensuring compliance with legislation, integral, complementary results at each stage of customs operations, implemented in interaction with all its elements, as well as with external systems, primarily with the tax service. The main places for the implementation of consistent and complementary customs control are:

1) checkpoints;

2) places of declaration and release of goods;

3) places of transportation, storage or sale of goods.

At each stage of the control, it is necessary to collect its results in an amount sufficient to make decisions on the possibility of carrying out subsequent operations or on their completion, or on the need for additional forms of customs control or the use of individual measures to ensure its implementation, or on the required volume of control operations on the subsequent stages of customs operations, thereby forming a system of end-to-end control in relation to goods being moved and people engaged in foreign economic activity which uses the current information flow and the results of actions of customs authorities as mutually complementary elements.

The need to form a system of end-to-end control is expounded in Article 222 of the Law on Customs Regulation, and has been repeatedly raised by various authors [2, 3]. But in full measure, in practice, it has not been possible to create such a system so far. Commonly, the end-to-end control system is considered at the level of interaction between various state bodies [3], but in this article, the authors also consider it from the point of view of the internal interaction of the customs authority's divisions, as a basic component of the control system.

The starting point of the end-to-end control system should be the checkpoint where there are ample opportunities for collecting information about the objects being moved and for exercising control. The modernization of checkpoints should take into account, first of all, not compliance with the uniform requirements for the technical equipment of checkpoints

[4], but the possibility of creating an integral control.

Inspection complexes that provide images of all consignments with the ability to intelligently process them and compare them with the information contained in accompanying documents can become a key source of data for increasing information content. To implement this mechanism, it is required to form new 
parameters of the checkpoint taking into account the best world practices and strategic objectives of the state, as well as modern technological solutions, and to develop a new procedure for its operation [5].

The next point for collecting information and carrying out control is the place of goods declaration. The current trend towards a reduction in the time of customs clearance indicates the limitations of the possibility of carrying out additional forms and control measures at the

stage of customs clearance, therefore, the role of information from adjacent stages, i.e. the checkpoint and control after release, increases. In this configuration, the control system can be configured in such a way that the initial data obtained at different stages, using the risk management system $[6,7]$, would make it possible to make the most accurate decisions about the need for actual control or about forming the basis for making a decision on conducting control after the release of goods. In the context of the tendency to reduce the time of customs clearance, the expansion of control capabilities remains only at the stage after the release of goods.

According to the Federal Customs Service of Russia, in 2020, about 80,000 participants carried out foreign economic activity. Let us assume that $30 \%$ of them are high-risk, $40 \%$ are medium-risk, and $30 \%$ are low-risk level [8]. For 9 months of 2020, 1,147 inspections were carried out (in 2018 - 2,100 inspections). In total, a little more than 5,000 companies, or $6.25 \%$ of their total number, were inspected in 3 years. Given such dynamics, it will take 12 years to check the participants in foreign economic activity related to a high level of risk. Without significant changes aimed at increasing the coverage of checks after the release of goods, it will not be possible to achieve the effectiveness of customs control in general.

It should be noted that the powers of the customs authorities also extend to participants in trade relations that are not participants in foreign economic activity, but they sell goods, and the volume of violations identified in relation to them is constantly growing. All the mechanisms for the introduction of labelling and traceability of goods do not fully achieve the goal, since the supply chain of goods from the moment of importation to the moment of sale to the end consumer can be brought into the shadows (cash payments, sales in the markets etc.).

It is extremely difficult to implement any one universal approach to change the situation since the customs authorities have to deal with 3 categories of inspected people: 1) those complying with the legislation;

2) participants with no history or having repeated violations;

3) participants not carrying out legal foreign trade turnover of goods.

In each case, you need your own tools to achieve results.

For the first category, it is necessary to best support possible conditions that provide the opportunity to use legal methods to eliminate the identified errors. Assuming they are not intentional and the company will seek to eliminate them if identified. In addition, it is important to create conditions to encourage other participants to move into this category.

The introduction of the institution of customs audit can be the basis for carrying out verification activities for the first category.

By customs audit, the authors mean a check of financial statements and business transactions of an importer, exporter and seller of goods, carried out by an independent organisation on the basis of plans (tasks or algorithms) approved (agreed) by the customs authorities. The conclusion based on the results of the 
audit will express an independent opinion on the reliability of the information and compliance with the legislation, and should allow the inspected people to eliminate the identified deficiencies without bringing them to administrative responsibility.

Such conclusions could expand the volume of information on the activities of foreign economic activity participants and become part of the system of end-to-end customs control. Foreign experience indicates the feasibility of implementing this approach [9-11]. This approach makes it possible to delegate certain powers of the customs authorities without detracting from the effectiveness of control [12].

The data obtained from auditors can be used to move from control to monitoring the activities of participants in foreign economic activity related to a low level of risk [4], as well as it can be used in the framework of interaction between the customs services of the EAEU [13].

For the second category of participants in foreign economic activity, the institution of customs audit is of little use, but it should be an incentive to reduce the administrative burden. The resources freed from the activities must be used in relation to the illegal sector. According to the FCS of Russia, the results of work in relation to people engaged in trade operations with goods that have not passed customs clearance are constantly improving. However, in addition to the administrative impact, it is necessary:

1) to develop a mechanism that allows legitimate purchasers to declare goods illegally imported by other people;

2) to simplify for the customs authorities the procedure for carrying out a full cycle of measures when detecting illegally imported goods (availability of storage places, the procedure for selling these goods);

3 ) to conduct an information campaign informing not only about the inevitability of prosecution, but also about legal ways to solve the existing problems of entrepreneurs; 4) to create a mechanism to provide information on the procedure for organisations to act if they want to get out of the shadow sector of the economy;

As a result, a system will be formed that will ensure the collection of objective data and allow you to concentrate on the most risky objects, form incentives and mechanisms for voluntary elimination of errors by participants in foreign economic activity, or for changing their activities and leaving the shadow sector, will also provide a high probability of detecting violations and responsibility for them. The system will allow establishing a balance between the level of customs control and simplifications for foreign trade participants [14].

\section{Conclusion}

The analysis has showed that in order to eliminate the existing problems and shortcomings in the customs control system, it is necessary to build a system of end-to-end control based on the application of various approaches to participants in trade relations in cooperation with other state regulatory authorities, using the institution of customs audit and a mechanism to stimulate companies to exit from the shadow economy.

The key effect from the implementation of the proposals will be an increase in budget revenues (up to 1 trillion rubles), a reduction in the share of the shadow economy and an increase in the transparency of operations.

Proposals for improving the control system can be implemented in the process of 
improving the activities of customs and other state regulatory bodies of the EAEU member states.

\section{References}

1. On the Strategy of Economic Security of the Russian Federation for the Period until 2030, Decree of the President of the Russian Federation of May 13, 2017, No. 208 (2017)

2. E.G. Anisimov, V.G. Anisimov, T.N. Saurenko, Bulletin of the Russian Customs Academy, 1, 14-19 (2015)

3. E.G. Bormotova, N.G. Lipatova, Mezhvedomstvennoe informacionnoe vzaimodejstvie dlya obespecheniya vypolneniya kontrolnyh funkcij tamozhennymi organami [Interdepartmental information interaction to ensure the performance of control functions by customs authorities] (Publishing House of the Russian Customs Academy, Moscow, 2014)

4. On Uniform Standard Requirements for Equipment and Material and Technical Equipment of Buildings, Premises and Structures Necessary for Organising State Control at Checkpoints across The Customs Border of the Eurasian Economic Union, Customs Union Commission Decision of June 22, 2011, No. 688 (2011) 5. A.A. Berzan, S.A. Miklava, Transformatsiya kontrolnoi deyatelnosti v punktakh propuska cherez gosudarstvennuyu granitsu v novykh ekonomicheskikh realiyakh [Transformation of control activities at checkpoints across the state border in the new economic realities], in Economic strategies of the EEU: Problems and innovations: Collection of Materials of the III All-Russian Scientific and Practical Conference, 2020, RUDN, Moscow (2020). Accessed on: July 23, 2021. [Online]. Available: https://elibrary.ru/item.asp?id=44059897 6. A.M. Sorokin, Bulletin of the Russian Customs Academy, 3, 150-154 (2015) 7. A.A. Berzan, M.Yu. Timchenko, Journal of Management Research, 5(2), 48-56 (2019) 8. The Netherlands Tax and Customs Administration. Horizontal Monitoring within the Medium to very Large Businesses Segment. Accessed on: July 23, 2021. [Online]. Available: belastingdienst.nl

9. Yu. Aoyama, World Customs Journal, 2(1), 95-100 (2008)

10. A.V. Agapova, Scientific Journal of NRU ITMO (National Research University of Information Technologies, Mechanics and Optics). Economics and Environmental Management Series, 4, 7-13 (2014)

11. I.V Gorelova, E.S. Butenko, Customs and foreign economic activity of companies, 1(2), 170-182 (2017)

12. O.V. Romanovskaya, Bulletin of Perm University. Legal Sciences, 36, 143-154 (2017). https://doi: 10.17072/1995-4190-2017-36-143-154

13. V.I. Berezyuk, Accounting. Analysis. Audit, 3, 35-41 (2016)

14. C. Morini, P. Costacurta de Sá Porto, E. Inacio, World Customs Journal, 11(2), 23-36 (2017) 